\title{
Nucleoporin 153 regulates estrogen-dependent nuclear translocation of endothelial nitric oxide synthase and estrogen receptor beta in prostate cancer
}

\author{
Agnese $\mathrm{Re}^{1}$, Claudia Colussi ${ }^{1}$, Simona Nanni ${ }^{2}$, Aurora Aiello ${ }^{1,2}$, Lorenza Bacci ${ }^{2}$, \\ Claudio Grassi ${ }^{3,4}$, Alfredo Pontecorvi $\mathbf{i}^{2,4}$ and Antonella Farsetti ${ }^{1}$ \\ ${ }^{1}$ National Research Council (CNR), Institute of Cell Biology and Neurobiology (IBCN), Rome, Italy \\ ${ }^{2}$ Università Cattolica, Institute of Medical Pathology, Rome, Italy \\ ${ }^{3}$ Università Cattolica, Institute of Human Physiology, Rome, Italy \\ ${ }^{4}$ Fondazione Policlinico Universitario Gemelli, Rome, Italy \\ Correspondence to: Antonella Farsetti, email: antonella.farsetti@cnr.it \\ Claudia Colussi, email: claudia.colussi@cnr.it \\ Alfredo Pontecorvi, email: alfredo.pontecorvi@unicatt.it \\ Keywords: prostate cancer; Nucleoporin 153; eNOS; Estrogen Receptor signaling; molecular biomarkers \\ Received: September 22, $2017 \quad$ Accepted:May 07, $2018 \quad$ Published: June 15, 2018 \\ Copyright: $\mathrm{Re}$ et al. This is an open-access article distributed under the terms of the Creative Commons Attribution License 3.0 \\ (CC BY 3.0), which permits unrestricted use, distribution, and reproduction in any medium, provided the original author and source \\ are credited.
}

\section{ABSTRACT}

Nucleoporin 153 (Nup153), key regulator of nuclear import/export, has been recently associated to oncogenic properties in pancreatic and breast tumour cells modulating either cell motility and migration or gene expression by chromatin association.

In the present work, we have characterized the role of Nup153 in a cellular model of prostate cancer (PCa). The analysis of several immortalized cell lines derived from freshly explants of prostate cancer specimens showed that Nup153 protein was higher and present in multimeric complexes with eNOS and ER $\beta$ as compared to normal/hyperplastic prostate epithelial cells. This phenomenon was enhanced in the presence of $17 \beta$-estradiol $\left(E_{2}, 10^{-7} \mathrm{M}\right)$. Further experiments revealed that eNOS and ER $\beta$ were present in a DNA binding complexes associated with Nup153 promoter as demonstrated by ChIPs. Notably, after Nup153 depletion (siNup153), a reduction of migration capacity and colony formation in primary tumor-derived and metastatic PCa cells was observed. In addition, eNOS and ER $\beta$ nuclear localization was lost upon siNup153 regardless of $E_{2}$ treatment, suggesting that Nup153 is a key regulator of prostate cancer cell function and of the nuclear translocation of these proteins in response to hormone stimulus. Taken altogether our findings indicate that in PCa cells: $i$. the expression and function of Nup153 is modulated by estrogen signaling; ii. Nup153 contributes to cell migration and proliferation; iii. Nup153 regulates the nuclear translocation of eNOS and ERß by forming a multimeric complex. Our findings unveil Nup153 as a novel component of the estrogen-dependent multimeric complex, thus representing a potential therapeutic candidate in prostate cancer.

\section{INTRODUCTION}

Nucleoporins (NUPs) are components of the nuclear pore complex which spans the nuclear envelope and allows the transport between the cytoplasm and the nucleus.
Nucleoporin 153 (Nup153) is placed at the inner part of the nuclear envelope forming the nuclear basket with other peripheral NUPs, where it interacts with the nuclear matrix. Interestingly, several NUPs are capable, upon still unknown signals, to move to nucleoplasm and interact with chromatin, 
thus contributing not only to nuclear import/export but also to chromatin organization and gene expression regulation. Specifically, it has been recently demonstrated that Nup153 represents a new class of global chromatin-binding proteins regulating the spatial organization of chromosomes associating at very high density with transcriptionally active regions $[1,2]$. NUPs, including Nup153, appear to be implicated in a large number of disorders, such as cardiomyopathy associated to muscular dystrophy [2], autoimmune disease and cancer [3, 4]. In this regard, several reports established that NUPs regulate cancer through different mechanisms based either on the import of DNA repair proteins [5] or gene regulation [3]. Increased expression of Nup153 due to a $6 \mathrm{p} 22$ genomic translocation was detected in urothelial carcinoma and retinoblastoma $[6,7]$. Moreover, in a screening for genes, Nup153 was found amplified in the pancreatic cell line PL5 [8]. This study suggested an oncogenic function for Nup153 by modulating the TGF- $\beta$ signalling pathway. Furthermore, Nup153 is important for tumor cell migration and proliferation [9] which are essential features of metastatic cancers. Of note, Nup153 knockdown was responsible for the alteration of nuclear lamin A in these cancer cells. Indeed, the function of nuclear envelope and nuclear matrix are intimately connected and linked to chromatin structure and integrity and are often altered in cancer cells.

Previous works from others and our group identified a molecular mechanism that sustains the aggressive phenotype of prostate cancer (PCa) $[10,11]$. The endothelial nitric oxide (NO) synthase (eNOS) in fact, plays a key role in prostate tumor maintenance and progression by forming complexes with Estrogen Receptors (ERs) [12-14] which exert an epigenetic control of gene expression. Importantly, the localization of eNOS-containing nuclear complexes, as assessed by ChIP-Seq, shows a specific pattern in response to $17 \beta$-estradiol $\left(\mathrm{E}_{2}\right)$ treatment contributing to the acquisition of a pathological gene expression signature. Overall, these findings are in agreement with the concept that NO has a broad negative effects on cancer, sustaining cell malignant transformation, cancer progression and the metastatic cascade ([15] and references therein).

Here we report about the new role of Nup153 in a hormone-driven activation cascade, involving eNOS and NO production, which contributes to a transcriptional program associated with prostate cancer. In fact, hormone-dependent eNOS activation enhances Nup153 expression which is followed by nuclear import of eNOS/ER $\beta$ by the formation of eNOS/ER $\beta /$ Nup153 complexes. Our results suggest Nup153 as potential therapeutic target in prostate cancer.

\section{RESULTS}

\section{Nup153 regulates cell migration and colony formation in prostate cancer cells}

To investigate Nup153 potential contribution to the biology of prostate cancer two cellular models were adopted: human immortalized cell lines derived from freshly explanted prostate tumors obtained from patients with diagnosis of clinically localized disease and selected for the absence of hormonal neoadjuvant treatment before surgery [16] and the metastatic prostate cancer cell line LNCaP. We first evaluated whether Nup153 silencing by siRNA could affect migration and clonogenic ability of prostate cancer cells.

A significant reduction of migration capacity as well proliferation was found in primary tumor-derived (C27IM, not shown) and metastatic (LNCaP) PCa cells undergoing to Nup153 downregulation as shown by scratch test and colony formation assay (Figure 1A-1B). Nup153 silencing progressively reduced cell metabolic activity (Figure 1C), in agreement with its essential role in cell viability and control of cell cycle [17-19].

When we analysed Nup153 expression by confocal microscopy we found that in the unstimulated conditions Nup153 protein level was higher in PCa cells (C38IM and $\mathrm{C} 27 \mathrm{IM}$ ) as compared to Benign Prostate Hyperplasia (BPH) cells (C17IM) (Figure 1D, upper panels). Nup153 knockdown has been previously linked to alteration of the nuclear lamin A in breast cancer cells [9]. Interestingly, in PCa cells (C38IM and C27IM), that show increased level of Nup153, the organization of nuclear lamin A, was also altered and the nuclei showed irregular shapes with membrane invaginations and multiple lobes (Figure 1D, lower panels and right graph).

\section{Hormone-dependent eNOS activation regulates Nup153 expression in PCa cells}

Our PCa cell lines show a particular aggressive phenotype that we found to be mainly dependent on a basal higher estrogenic responsiveness that determines in turns eNOS and ER $\beta$ nuclear accumulation and complexes formation, which drive a pathological gene expression $[13,14]$. Thus, we reasoned that the higher basal level of Nup153 in PCa cells compared to BPH could be a consequence of a potential hormone-responsiveness of Nup153, mediated by eNOS activation, in prostate microenvironment [12-14, 20-24]. In order to understand the contribution of estrogenic signalling in this pathway, PCa cells were cultured for 72 hours in hormone-deprived serum and then treated or not with $17 \beta$-estradiol. In the above conditions, we analysed the regulatory region at 5 , Nup153 gene on our ChIP-Seq database [12]. Intriguingly this analysis revealed a hormone-dependent localization of eNOS-DNA association peaks along Nup153 extragenic/ intronic regions, strongly supporting the hypothesis of an estrogen-dependent regulation of Nup153 (Figure 2A). By an independent set of traditional ChIP in C27IM cells we validated the hormone-induced eNOS binding downstream to TSS within Nup153 genomic region, confirming that Nup153 is a transcriptional target of eNOS. In addition, an estrogen-dependent recruitment of 
ER $\beta$ was also found onto Nup153 promoter, suggesting the formation of a combinatorial chromatin complex eNOS/ER $\beta$ along that genomic region (Figure $2 \mathrm{~B}$ ). To further corroborate our finding a second antibody to ER $\beta$, the CWK-F12 [25, 26], also suitable for ChIP assays, was used, confirming recruitment of ER $\beta$ in basal as well in the estrogen-stimulated condition onto Nup153 promoter (Supplementary Figure 1).

We next investigated the responsiveness to $\mathrm{E}_{2}$ of Nup153 in terms of RNA and protein expression. To address

A
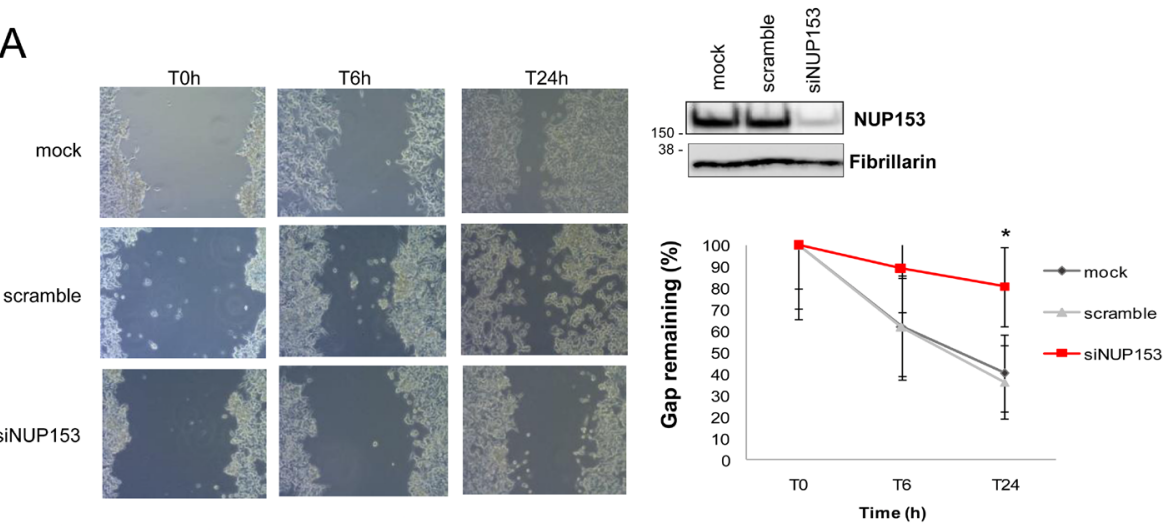

B
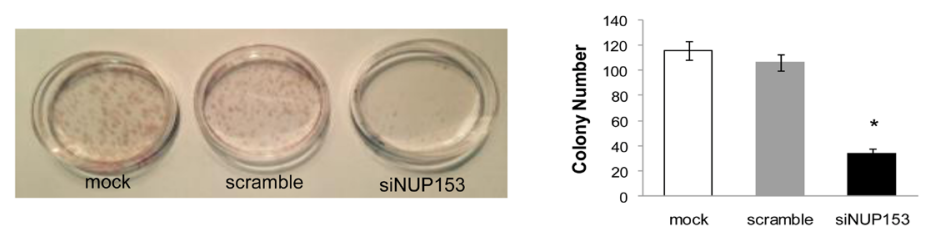

C
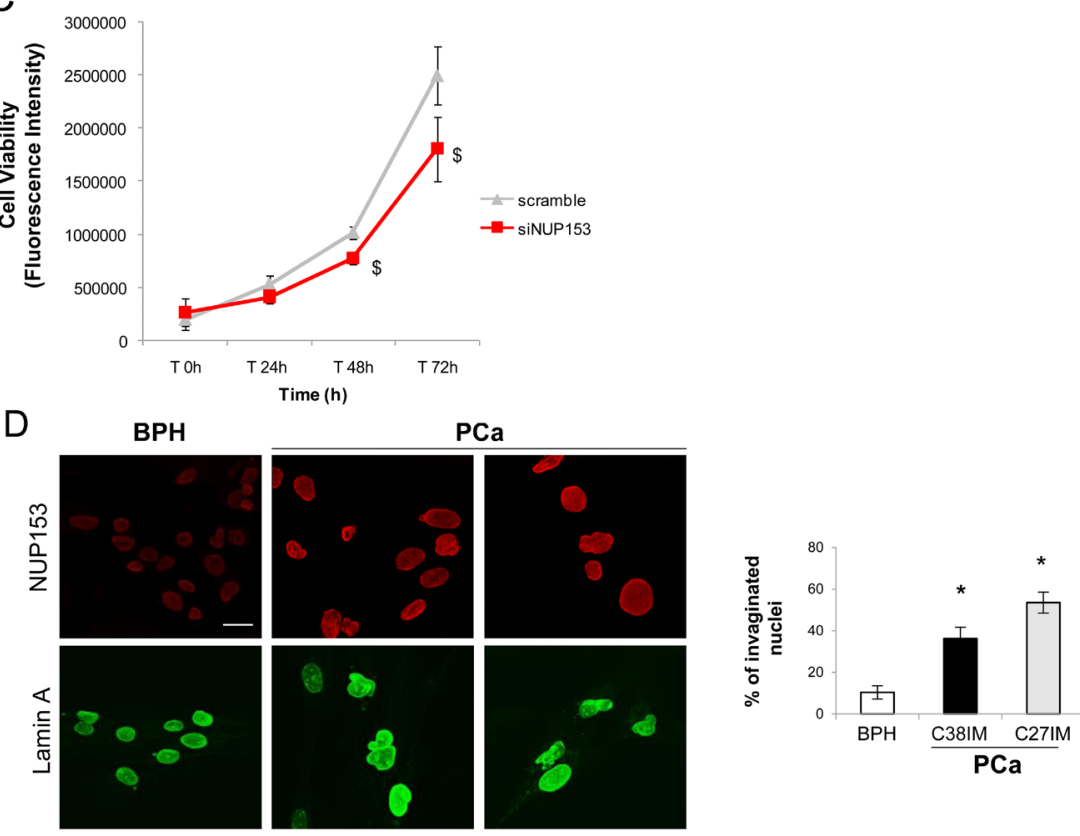

Figure 1: Nup153 depletion in PCa cells regulates migration and colony formation. (A) Representative phase contrast images (Bright field) of a scratch test in a time course of $24 \mathrm{~h}$ (left panel) and its quantification (right panel, down), expressed as percentage of remaining gap, in Nup153 silenced (siNUP153 oligos mix; 60nM), scramble control and mock transfected LNCaP cells. The wound was made $48 \mathrm{~h}$ after transfection. Nup153 protein level in the above conditions is shown in the western blot (right panel, up). (B) Left panel: Representative digital image showing colonies produced by PCa (C27IM) cells after plating 150 cells. Cells were transfected in the same experimental conditions of scratch test and, after eight days, were fixed and stained with hematoxilin. In the right panel, the number of colonies for each condition is shown. Data expressed as mean $+/-$ SEM of 3 independent experiments. ${ }^{*}$ p $<0.05$ vs mock. (C) Cell Viability in a time course of $72 \mathrm{~h}$ in the same experimental conditions as described for scratch test. Data are expressed as mean $+/-\mathrm{SEM}$ of 3 independent experiments in triplicate, corrected to fluorescence background. ${ }^{\$} \mathrm{p}<0.05$ vs scramble. (D) Confocal analysis of PCa (C27IM and C38IM) and Benign Prostatic Hyperplasia (BPH, C17IM) cells stained with antibodies to Nup153 ([QE5]; red) or Lamin A (green). Scale bar: $20 \mu \mathrm{m}$ (Nup153 and Lamin A). The graph shows the percentage of nuclei bearing invaginations (right panel). ${ }^{*} \mathrm{p}<0.05 \mathrm{vs}$ BPH. 
this point, quantitative RealTime PCR ( $q$ RT-PCR), western blot, and confocal microscopy were performed in $\mathrm{PCa}$ and BPH cells cultured for 72 hours in hormone-deprived serum and then treated with $17 \beta$-estradiol $\left(\mathrm{E}_{2} ; 10^{-7} \mathrm{M}\right)$ for 1, 3, 6 and 24 hours. In BPH cells Nup153 mRNA level was weakly affected by $\mathrm{E}_{2}$ treatment exhibiting a similar extent at each time course considered (Figure 2C), while an induction of Nup153 was observed in PCa cells. Similar results were obtained for Nup153 protein expression that was unaffected in BPH and induced in PCa cells by $\mathrm{E}_{2}$ treatment (Figure 2D). Hormone-driven Nup153 protein increase was prevented in the presence of 7-nitroindazole (7N) an inhibitor of the NOS function as demonstrated by confocal and western blot analyses (Figure 2E-2F). The key role of eNOS in regulation of Nup153 expression was confirmed using W7, an inhibitor of Calmodulin function, which is upstream of the eNOS activation, determining Nup153 downregulation in PCa cells (Figure 2G).

\section{Nup153 is part of a multimeric complex induced upon estrogen stimulation}

We previously demonstrated that eNOS nuclear import, followed by the formation of transcriptional complexes with ER $\beta$, occurs in PCa cells under basal condition and is enhanced under estrogen stimulus [13]. To understand whether and how Nup153 may take part of this activation pathway we investigated the possible formation of protein complexes potentially important for both eNOS nuclear translocation and its activation for transcriptional activity. We analysed the cells either in basal condition or after estrogenic deprivation (NT) followed or not by $\mathrm{E}_{2}$ treatment for $3 \mathrm{~h}$ and $45 \mathrm{~min}$ and/ or $24 \mathrm{~h}\left(\mathrm{E}_{2}\right)$. Confocal microscopy analysis revealed colocalization of eNOS and Nup153 predominantly in PCa cells in basal condition (Figure 3A). Quantification of double-labelled areas in BPH or PCa cells was $2 \% v s$. $38 \%$, respectively (not shown). Co-IP for eNOS (Figure 3B) confirmed an interaction between Nup153 and eNOS that was stronger in tumor (PCa, C38IM and C27IM) as compared to BPH (C17IM) cells used as normal control.

Additional Co-IP experiments were performed in PCa cells (C27IM), endogenously expressing ER $\beta$, before and after $E_{2}$ stimulation. Either immunoprecipitation for ER $\beta$ and Nup153, revealed that hormone treatment induced the formation of a trimeric complex containing eNOS, ER $\beta$ and Nup153 (Figure 3C). To reinforce our finding we used an alternative antibody proved highly specific for $\operatorname{ER} \beta$ and an additional cell line, HeLa, known to be ER-negative. We performed a Co-IP for Nup153 (Figure 3D) in HeLa transfected with human ER $\beta$ full-length in basal or upon $\mathrm{E}_{2}$ treatment. Results confirmed a specific interaction among Nup153, ER $\beta$ and eNOS in HeLa cells also using this different antibody for ER $\beta$.

Nup153 association with histone acetylases (HATs) regulates their activity in cardiomyocytes bearing dystrophin mutation [2]. Other reports also have shown that epigenetic enzymes function and chromatin association are regulated by nucleoporins [27]. Thus, we first investigated by Co-IP the potential Nup153 interaction with the HAT member p300 and found that $\mathrm{E}_{2}$ treatment strongly enhanced their association in PCa cells compared to un-stimulated and estrogen-deprived cancer cells (Figure $3 \mathrm{E}$ ). We found also, that $\mathrm{E}_{2}$ was capable of modulating the acetylase activity specifically associated with Nup153 (Figure 3F) suggesting the formation of a transcriptionally competent complex upon estrogen stimulation.

To explore further the role of Nup153 in the $E_{2}$ signalling we analysed the expression of VEGF Type 2 Receptor (VEGFR2/KDR), an $\mathrm{E}_{2}$-target gene, after Nup153 silencing and under hormone stimulation. Nup153 depletion virtually abrogated VEGFR2/KDR E responsiveness thus confirming Nup153 transcriptional role in this context (Figure 3G).

\section{Nup153 regulates eNOS and ER $\beta$ nuclear import in a hormone-dependent manner}

The evidence of the nuclear interaction between eNOS and ER $\beta$ with Nup153 prompted us to investigate whether Nup153 had a role in nuclear transport of these proteins. By confocal microscopy, we analysed eNOS and $\mathrm{ER} \beta$ nuclear shuttling, upon $\mathrm{E}_{2}$ treatment, in PCa cells that were silenced for Nup153 or treated with scramble oligo as control.

Nup153 expression was highly induced upon $\mathrm{E}_{2}$ treatment at the two time points (3h45min; 24h) and in parallel eNOS and ER $\beta$ were imported into the nucleus (Figure 4A-4B). However, Nup153 silencing strongly reduced the presence in the nucleus of eNOS and $\mathrm{ER} \beta$ both in NT and in $\mathrm{E}_{2}$ treated cells (Figure 4A-4B). Similar results were obtained in an additional immunofluorescence experiment performed with the validated antibody to $\mathrm{ER} \beta$ (CWK-F12, DHSB) and a rabbit antibody to Nup153 ([H-161], Santa Cruz) (Supplementary Figure 2).

To assess the specificity of Nup153-dependent eNOS and ER $\beta$ nuclear import we evaluated the effects of Nup 153 depletion on nucleo-cytoplasmic protein trafficking, with particular attention to the localization of the exogenous Green Fluorescent Protein (GFP), in p-GFP transfected cells, and the endogenous Histone deacetylase 2 (HDAC2) proteins. No modification of GFP and HDAC2 localization was indeed observed upon siNup153, thus indicating that inhibition of eNOS and ER $\beta$ nuclear translocation after Nup153 depletion is specific (Figure 4C-4D).

\section{DISCUSSION}

Many studies demonstrated a link between aberrant nuclear shape and tumorigenesis. Indeed, components 
of the nuclear envelope have been implicated in the regulation of several cell functions affected during cancer initiation and progression, such as proliferation, migration and DNA repair. In this context we have found that the nuclear pore component Nup153 plays a key role in the aberrant estrogen response of prostate cancer,
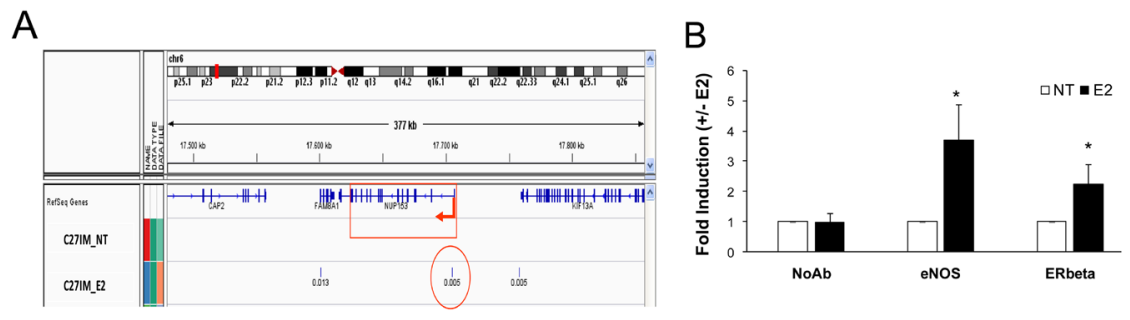

C

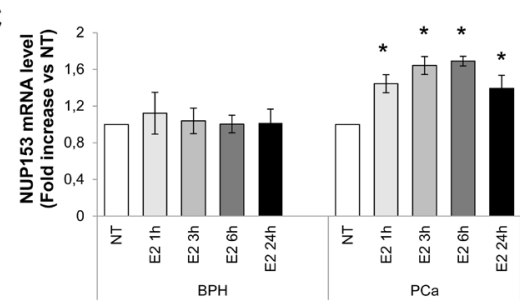

D

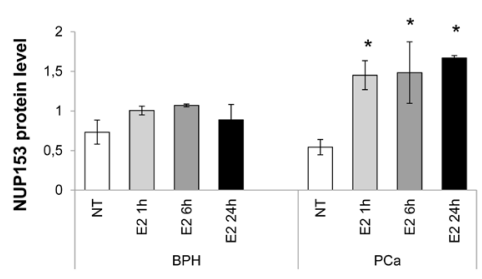

$\mathrm{E}$

DAPI

NUP153
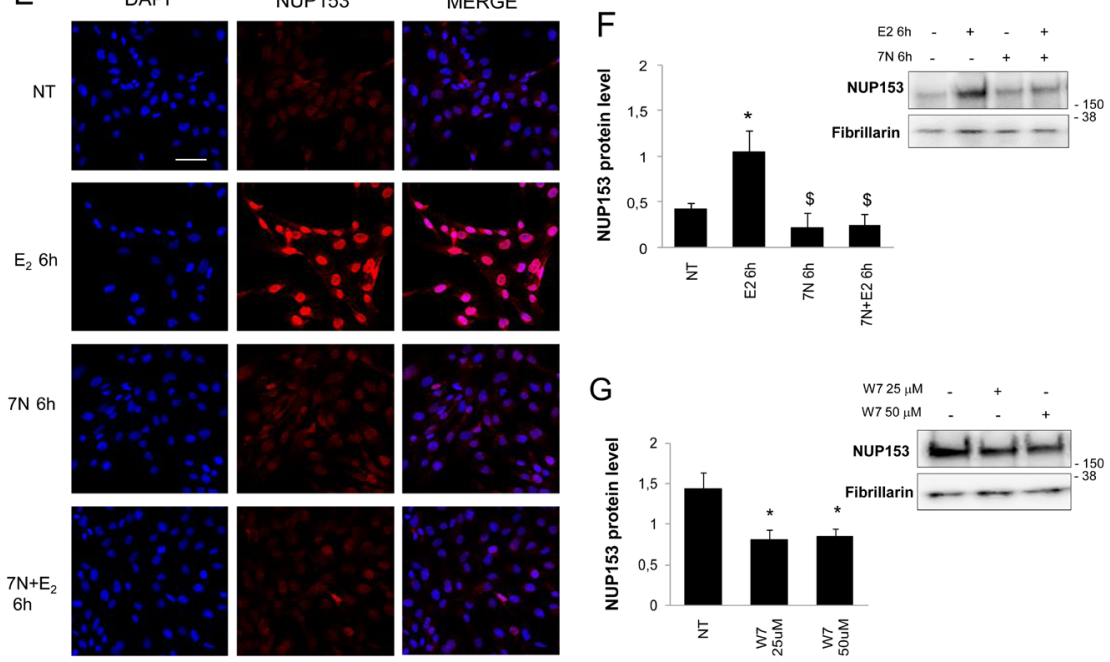

Figure 2: eNOS binds Nup153 promoter and regulates its expression in an estrogen-dependent manner. (A) Integrated Genome Viewer (IGV 2.3) screenshot showing peaks of eNOS identified by ChIP-Seq at the genomic regions encoding Nup153 in PCa cells $(\mathrm{C} 27 \mathrm{IM})$ in the absence $(\mathrm{NT})$ or presence of $17 \beta$-estradiol $\left(\mathrm{E}_{2}, 10^{-7} \mathrm{M}, 45 \mathrm{~min}\right)$. Region amplified in panel $\mathrm{B}$ is indicated with a red circle. (B) Recruitment of eNOS and ER $\beta$ on the promoter region of Nup153 by ChIPs in the presence or absence of $\mathrm{E}_{2}(45 \mathrm{~min})$ in $\mathrm{C} 27 \mathrm{IM}$ cells. The immunoprecipitations were performed using anti-eNOS (Type III, BD), anti-ER $\beta$ (L-20) or no antibody (NoAb) as a negative control. Values are represented as fold of induction $\left(+/-\mathrm{E}_{2}\right)$ and as mean $+/$-SEM of 3 independent experiments. " $\mathrm{p}<0.05$ E $\mathrm{E}_{2}$ vs NT. (C) Nup153 mRNA levels quantified by $q$ RT-PCR in PCa and BPH cells in basal condition (NT) and after $\mathrm{E}_{2}$ in a time course of $1,3,6$ or 24 hours. The results are plotted as fold induction vs NT +/-SEM of 3 independent experiments. ${ }^{*}<0.05 \mathrm{E}_{2}$ vs NT. (D) Nup153 protein levels were analysed by western blot in PCa and BPH cells in a time course of 1, 6 or 24 hours. Numbers represent optical density analysis of bands normalized to loading control. Data are mean + -SEM of 3 and 4 independent experiments for BPH and PCa, respectively. " $\mathrm{p}<0.05 \mathrm{vs}$ NT. (E) Confocal analysis of Nup153 ([QE5]; red) in PCa cells untreated (NT) or treated with $\mathrm{E}_{2}\left(10^{-7} \mathrm{M}\right)$ and/or $7 \mathrm{~N}(0.5 \mathrm{mM})$ for 6 hours. Nuclei were counterstained with DAPI (blue) and merged with the Nup153 signal (red). Scale bar $25 \mu \mathrm{m}$. (F-G) Protein level analysis of Nup153 before and after $\mathrm{E}_{2}\left(10^{-7} \mathrm{M}, 6 \mathrm{~h}\right)$ alone or in combination with $7 \mathrm{~N}(0.5 \mathrm{mM}, 6 \mathrm{~h})(\mathrm{F})$ and upon W7 (G) treatment $(25 \mu \mathrm{M}$ and $50 \mu \mathrm{M}$, overnight). Right Panel: Representative western blot of Nup153. Fibrillarin served as loading control. Left Panel: Numbers represent optical density analysis of bands normalized to loading control. Data are mean +/-SEM of 3 for W7 and 4 for $7 \mathrm{~N}$ independent experiments. ${ }^{*} \mathrm{p}<0.05$ vs NT; ${ }^{\$} \mathrm{p}<0.05$ vs $\mathrm{E}_{2}$. 

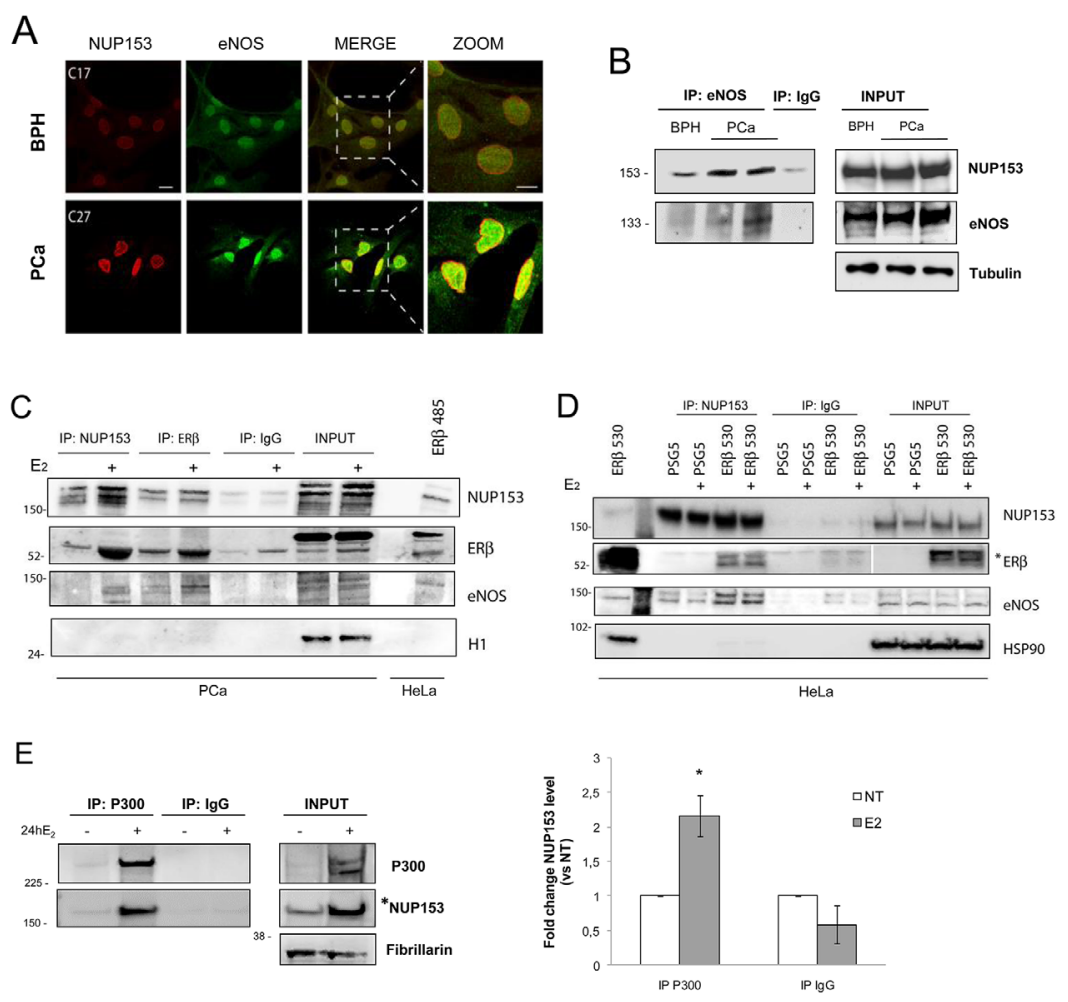

$\mathrm{F}$

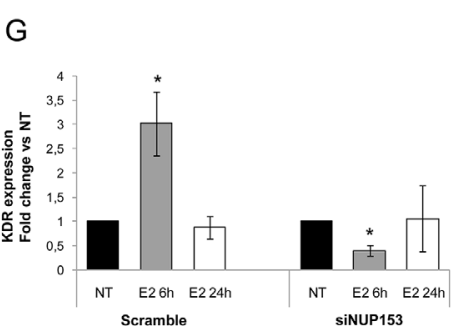

Figure 3: Nup153 forms complexes with eNOS, ERß and p300. (A) Confocal analysis of Prostate Cancer (PCa, C27IM) and Benign Prostatic Hyperplasia (BPH, C17IM) cells stained with antibodies to Nup153 ([QE5]; red) or eNOS (Type III; green). Scale bar: $20 \mu \mathrm{m}$ (Nup153, eNOS and MERGE; zoomed area is showed). (B) Analysis of Nup153 interaction with eNOS by Co-Immunoprecipitation in PCa and BPH cells in basal condition. Immunoprecipitation with IgG served as negative control. (C) Analysis of Nup153 interaction with eNOS and ER $\beta$ by Co-Immunoprecipitation in PCa cells in basal condition or upon $\mathrm{E}_{2}$ treatment $\left(10^{-7} \mathrm{M}, 24 \mathrm{~h}\right)$. PCa cells were immunoprecipitated with Nup153 Antibody ([7AB], Abcam) or with ER $\beta$ (GeneTex, \#110607). Immunoprecipitation with IgG served as negative control. Membranes were blotted with specific antibodies to Nup153 ([Q5], Abcam), ER $\beta$ (GeneTex, \#110607) and eNOS (Type III, BD). H1 served as control. $4 \mu \mathrm{g}$ of transfected HeLa with human ER $\beta$ short isoform (485aa) were used as positive control for Estrogen Receptor. Total proteins were resolved by SDS-PAGE using a 10\% Invitrogen precast gel (NuPage and MES buffer). (D) Analysis of Nup153 interaction with eNOS and ER $\beta$ by Co-Immunoprecipitation in HeLa cells transfected with empty vector (PSG5) or with human ER $\beta$ full-length (ER $\beta$ 530aa), before and after $\mathrm{E}_{2}$ treatment $\left(10^{-7} \mathrm{M}, 24 \mathrm{~h}\right)$. HeLa cells were immunoprecipitated with Nup153 Antibody ([7AB], Abcam). Immunoprecipitation with IgG served as negative control. Membranes were blotted with specific antibodies to Nup153 ([QE5], Abcam), ERß (CWK-F12, DHSB) and eNOS (Type III, BD). Hsp90 served as control. Total cell lysates (15 $\mu$ g) from HeLa transfected with human ER $\beta$ 530aa isoform were used as positive control for Estrogen Receptor. ${ }^{*}$ indicates a lower exposure for INPUT and positive control, respectively. Total proteins were resolved by SDS-PAGE using a 3-8\% Invitrogen precast gel (NuPage and TA buffer). (E) Analysis of Nup153 interaction with Histone Acetyl Transferase p300 by co-immunoprecipitation in PCa cells in basal condition or upon $\mathrm{E}_{2}$ treatment $\left(10^{-7} \mathrm{M}, 24 \mathrm{~h}\right)$. Immunoprecipitation with $\mathrm{IgG}$ was used as negative control. Fibrillarin served as loading control. * indicates a lower exposure for INPUT. Densitometric analysis showing, in the right panel, the interaction of Nup153 with p300 in $\mathrm{E}_{2}$ treated samples versus NT, normalized to input loading control and expressed as fold change. Data are mean $+/$-SEM of 3 independent experiments. " $\mathrm{p}<0.05$ vs NT. (F) Evaluation of HAT activity specifically associated with Nup153 in total extracts of PCa cells cultured in absence or in presence of $\mathrm{E}_{2}\left(10^{-7} \mathrm{M}, 24 \mathrm{~h}\right)$ and subjected to immunoprecipitation with anti-Nup153 antibody ([7AB], Abcam) or normal IgG immunoglobulin as negative control. Data are expressed as mean $+/$-SEM of 3 independent experiments. A.U. Arbitrary Unit *p $<0.05 \mathrm{E}_{2}$ vs NT. (G) Effect of Nup153 depletion on estrogen response gene. VEGF Type2 Receptor (KDR) mRNA levels quantified by $q$ RT-PCR in PCa cells before (scramble) and after Nup153 depletion (siNUP153 oligos mix, $60 \mathrm{nM}$ ), untreated or treated with $\mathrm{E}_{2}\left(10^{-7} \mathrm{M}, 6\right.$ and/or 24 hours). The results are plotted as Fold change vs NT, +/-SEM of 5 independent experiments. ${ }^{*}<0.05 \mathrm{E}_{2}$ vs NT. 
promoting the nuclear import of important determinants of transcription such as ER $\beta$ and eNOS which have been demonstrated to cooperate in driving the pathological gene signature.
Moreover, under estrogen induction, these effectors bind to Nup153 promoter region, increasing its protein level and consequently the nuclear import of eNOS/ER $\beta$ thus amplifying the effects on gene expression alteration

A
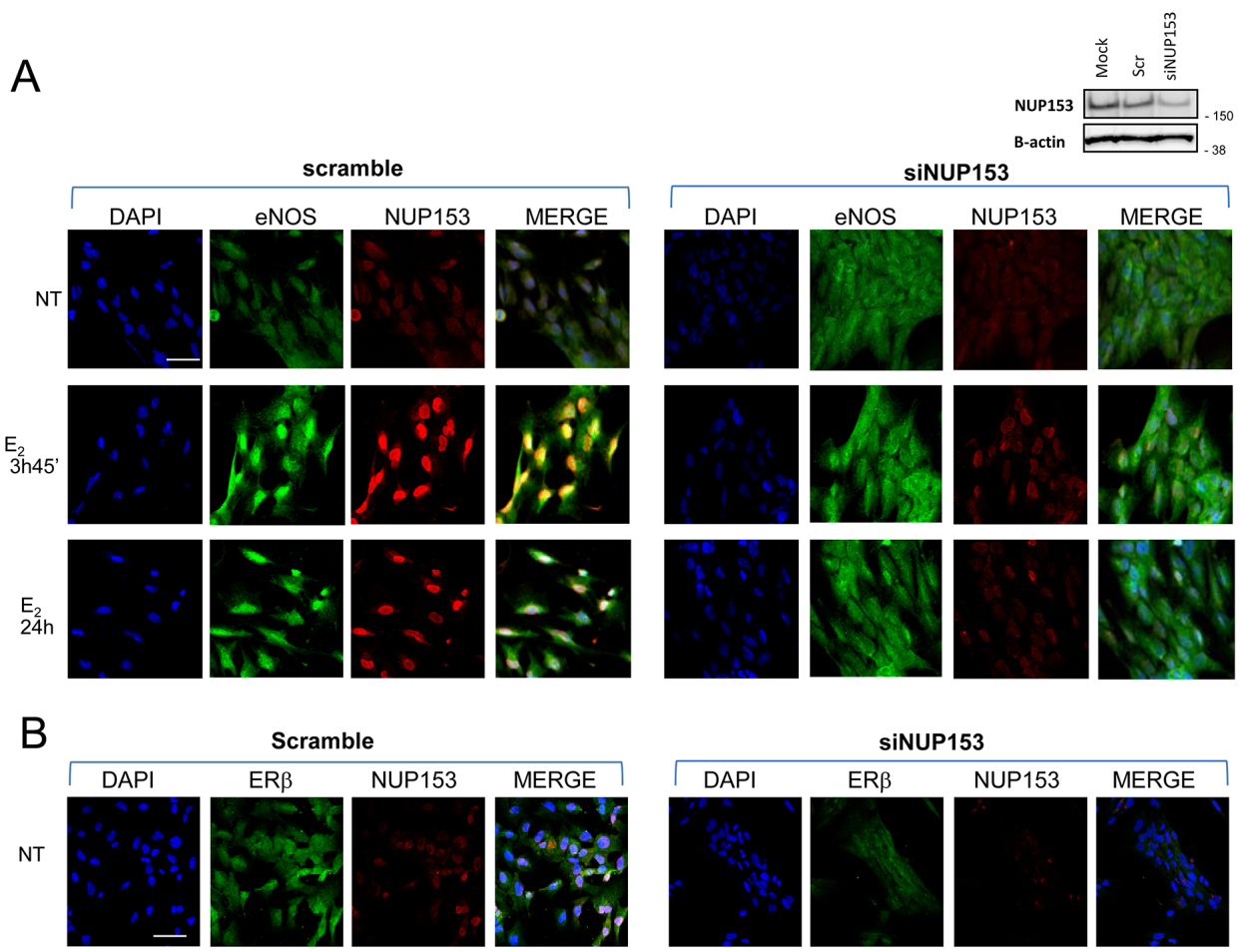

Scramble
ER $\beta \quad$ NUP153 MERGE
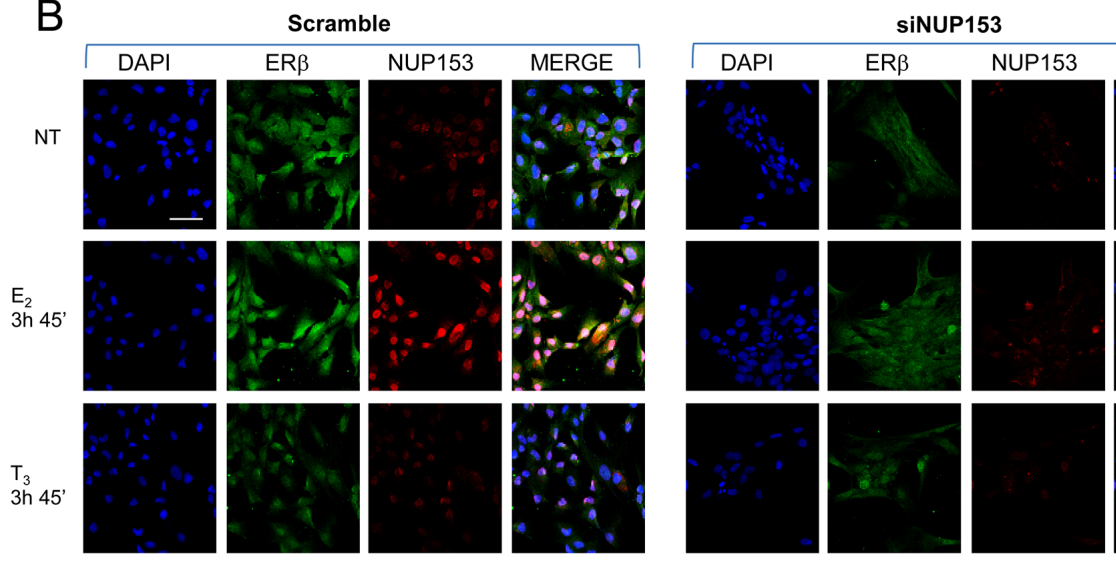

MERGE
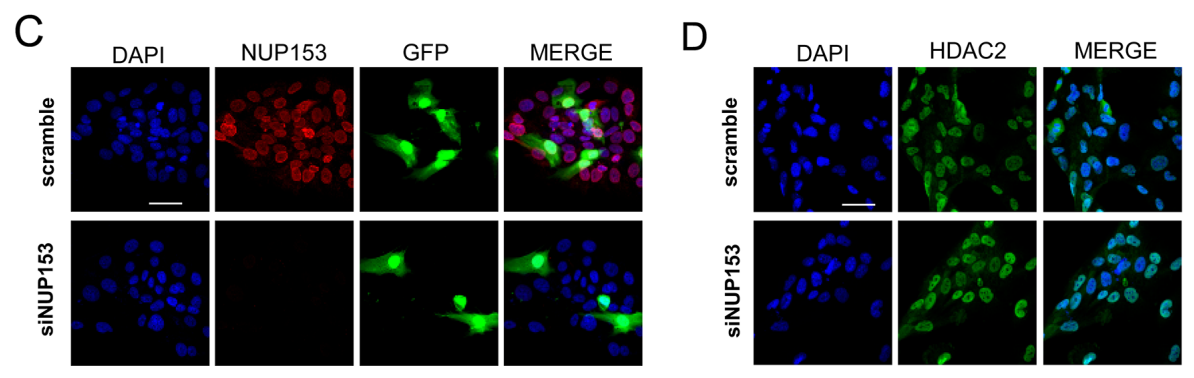

Figure 4: Nup153 controls eNOS and ERß nuclear translocation. (A-B) Representative confocal microscopy images of eNOS (A) or ER $\beta$ (B) nuclear localization (green) in PCa cells before and after Nup153 depletion, untreated or treated with $\mathrm{E}_{2}\left(10^{-7} \mathrm{M}\right.$, $3 \mathrm{~h} 45 \mathrm{~min}$ and/or 24 hours). Cells silenced for Nup153 (oligos mix, 60nM) or treated with scramble control oligo were analysed at $48 \mathrm{~h}$ post-transfection. $\mathrm{T}_{3}$ treatment $\left(10^{-7} \mathrm{M}, 3 \mathrm{~h} 45 \mathrm{~min}\right)$ served as control of ER $\beta$ estrogen response specificity. Nuclei were counterstained with DAPI (blue) and merged with the Nup153 ([QE5], Abcam; red) and eNOS (Type III, BD; green) or ER $\beta$ (Genetex \#110607; green) signals. Efficiency of Nup153 interference is assessed also by western blot (right upper panel A). (C) Representative confocal microscopy images of GFP localization in PCa-GFP transfected cells before and after Nup153 depletion. Nuclei were counterstained with DAPI and merged with the two protein signals (GFP in green and Nup153 [QE5] in red). Scale bar $50 \mu \mathrm{m}$. (D) Representative confocal microscopy images of HDAC2 localization (green) in PCa cells before and after Nup153 depletion. Nuclei were counterstained with DAPI and merged with the HDAC2 signal (green). Scale bar $50 \mu \mathrm{m}$. 
and contributing to tumor aggressiveness and the negative prognosis for $\mathrm{PCa}$.

The metastatic form of prostate cancer, in fact, is generally refractory to therapy and leads rapidly to death. Although the mechanistic control of prostate cancer cell metastasis is still poorly characterized, it is recognized as a multi-step process in which the epithelial-mesenchymal transition and the acquisition of enhanced cell motility largely contribute to the acquisition of the metastatic phenotype.

Our results showing that Nup153 positively regulates cell migration and is associated with aberrant nuclear structure in $\mathrm{PCa}$ is in line with previous findings describing the role of this nucleoporin in nuclear shaping and cell motility in other cancers [9].

Nucleoskeleton and cytoskeleton are intimately connected through the LINC complex [28] thus changes in nuclear structural proteins such as Nup153 and Lamins, may directly affect cell migration increasing the nuclear plasticity necessary for cell deformation during intra-extravasation process that characterizes metastatic cells [3]. Another important finding of our work regards the positive effect of Nup153 on the clonogenic capacity of prostate cancer cells thus suggesting that targeting this protein could represent a possible therapeutic strategy to counteract tumor growth. In fact, NUPs are important regulators of cell cycle either by taking part in the assembly-disassembly process during mitosis or by export of cell cycle inhibitors [29].

In the present study, we found that Nup153 is overexpressed in primary and metastatic PCa tumor cells as compared to benign lesions. Chromatin immunoprecipitation analysis suggests that a complex encompassing eNOS and ER $\beta$ is present on Nup153 promoter region and may then regulate its transcription as previously reported for other genes belonging to a prognostic signature including the telomerase catalytic subunit [13].

In prostate cancer the estrogen responsiveness, high levels of ER $\beta$ expression [30] associated with nuclear accumulation of eNOS [13] may represent a negative prognostic condition. Although the signal triggering Nup153 expression is still unclear we observed that Nup153 expression was induced by estrogens and associated with the estrogen property to upregulate the intracellular synthesis of nitric oxide (NO). Inhibitors affecting NO synthesis or eNOS activation pathway, in fact, abrogated the estrogen-dependent Nup153 protein increase. This observation is of particular interest indicating that both estrogens and NO may cooperate and contribute to aggressiveness in prostate cancer [13] through Nup153 upregulation.

Prior work described that Nup153 is involved in epigenetic processes aimed at controlling nuclear trafficking and gene expression [31]. Intriguingly, Nup153 has be found associated with chromatin in different cellular contexts possibly facilitating expression of a number of target genes via microRNAs and small interfering RNAs $[1,32]$. In this light, the association of Nup153 with both ER $\beta$ and eNOS in a trimeric complex not only is required for nuclear co-translocation of these proteins, but also could function as epigenetically active scaffold allowing their activity.

The association of Nup153 with other epigenetically active components has been previously reported in different conditions. Specifically, nucleoporins association

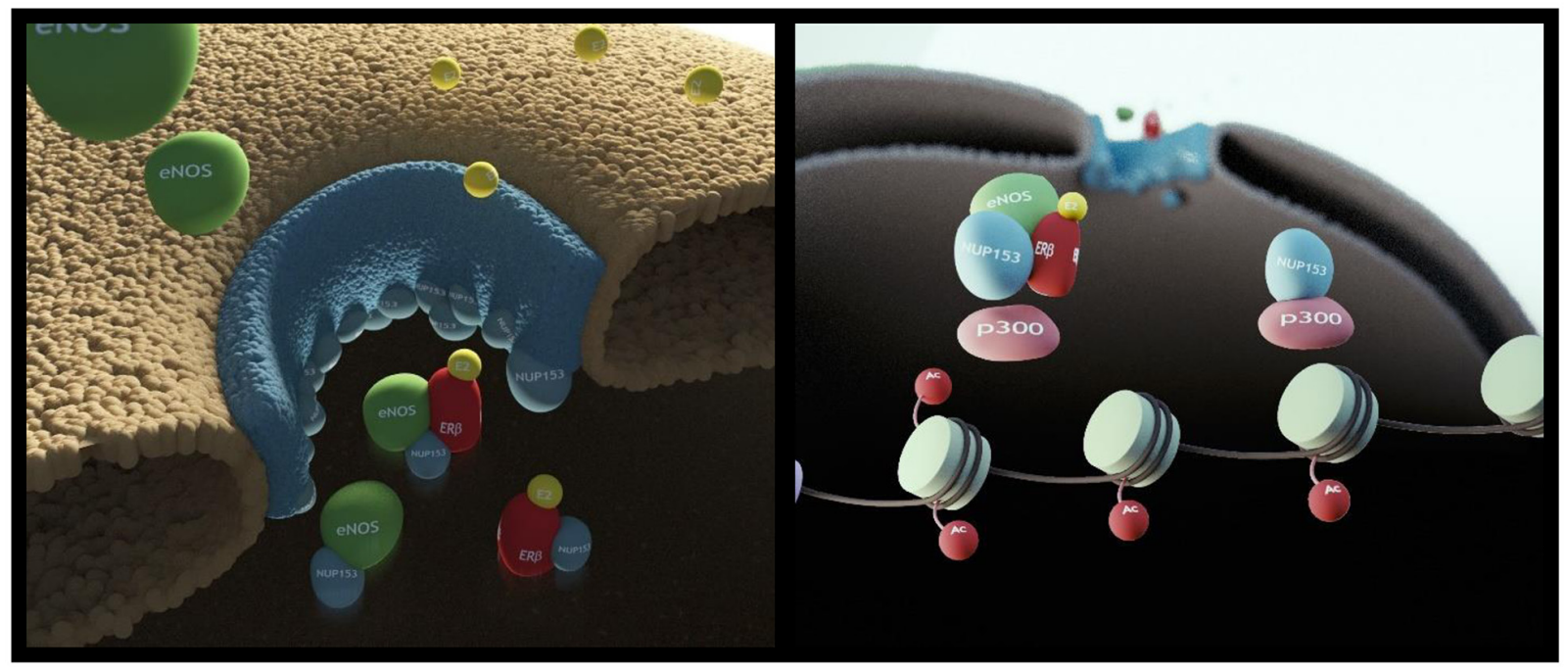

Figure 5: Cartoon depicting the proposed role for Nup153 as regulator of eNOS and ERß nuclear translocation and as scaffold for p300. Specifically, Nup153 binds eNOS and ER $\beta$ and drives their nuclear translocation. Once in the nucleoplasm Nup153 interacts with p300. Estrogen signaling affects Nup153 function by favouring its association with eNOS, ER $\beta$ and p300 and by increasing the acetylase activity specifically associated with Nup153. 
with HDACs has been shown important for their proper chromatin localization and gene regulation [27, 33, 34]. Prior studies, however, indicated that Nup153 could be acetylated in the heart of dystrophic mice. In this context, it has been found associated with lysine acetylases including p300 and PCAF [2]. These epigenetic enzymes function as transcription co-activators facilitating the expression of genes present in the chromatin region to which they are associated. Remarkably, lysine acetylases are always present as cofactors in nuclear hormone receptor complexes including those in which $\operatorname{ER} \beta$ is present [35]. In our study, it also emerged that p300 was associated with Nup153 in prostate cancer cells. This experimental evidence together with the specific Nup153-associated histone acetylase activity significantly incremented in the presence of estradiol is suggestive of a functional regulatory loop determining an estrogendependent Nup153 protein complex formation (see cartoon in Figure 5). In conclusion, the present report highlights the role of the nuclear envelope environment as a new player in prostate cancer cell biology. In response to estrogens and nitric oxide, Nup153 in fact, regulates ER $\beta$ and eNOS function through a coordinated nuclear import and providing an epigenetic scaffold for complex formation and appropriate release of the transcriptionally competent complexes in the nucleoplasm. The pathological gene expression that is estrogen-dependent in $\mathrm{PCa}$ is a major determinant of bad prognosis and of refractory and metastatic tumors. In this light, although further studies are required, our findings may suggest that, in addition to standard interventions, targeting Nup153 could be a potential new strategy. In fact, Nup153 depletion or inactivation could block the pathological estrogen signaling that sustains the aberrant gene expression in prostate cancer cells thus helping to normalize their epigenetic profile, to reduce proliferation and migration with important effects on their aggressive phenotype and cancer recurrence. This concept is indeed substantiated by our finding of abrogation of the VEGFR2/KDR estrogen responsiveness upon siNup153, given the relevance of the VEGF-VEGFR2 signaling in tumor-associated angiogenesis. Thus, in conclusion, the multiple roles played by Nup153 in prostate cancer cells makes it a potential powerful target to counteract tumor aggressiveness.

\section{MATERIALS AND METHODS}

\section{Antibodies}

The following antibodies were used: antiERß[L-20] (\#sc-6822), anti-p300 [C-20] (\#292438), anti-Nup153[H161] (\#sc-292438) from Santa Cruz Biotechnology, Dallas TX, USA; anti-ER $\beta$ from GeneTex (\#110607), Irvine, CA, USA and CWK-F12 from DSHB, Iowa City, IA, USA; anti-eNOS Type III (\#610299) from
BD Biosciences, Franklin Lakes, NJ, USA; anti-Nup153 [QE5] (\#Ab24700) for WB and confocal microscopy, and [7A8] (\#Ab93310) for Co-IP from Abcam; anti-Fibrillarin [38F3] from Pierce (\#MA3-16771); anti-Lamin A [131C3] (\#Ab8984) from Abcam; anti-tubulin from Immunological Science (\#MAB-10285); anti-HSP90 (\#SPC-104C) from StressMarq Biosciences Inc; anti-mouse FITC (\#715095150) and anti-rabbit TRITC (\#711025152) from Jackson Immunological Research.

\section{Cell culture and treatments}

PCa (C27IM, C11IM and C38IM), LNCaP and HeLa cell cultures and treatments were as in [12-14, 36]. All media were supplemented with $10 \%$ fetal bovine serum, $2 \mathrm{mM}$ glutamine, $100 \mathrm{ug} / \mathrm{ml}$ penicillin and streptomycin. At least $72 \mathrm{~h}$ before experimental use, cells were switched to a medium with hormone-deprived serum and treated with $17 \beta$-estradiol $\left(\mathrm{E}_{2}\right)$, triiodothyronine $\left(\mathrm{T}_{3}\right)$, $\mathrm{N}$-(6-Aminohexyl)-5-chloro-1-naphthalenesulfonamide hydrochloride (W7) or 7-nitroindazole $(7 \mathrm{~N})$, for the concentrations and the times indicated in the figure legends.

\section{Scratch test}

Scratch assay was performed as described in [37]. Briefly, cells were transfected and cultured to confluence. The monolayer was scraped with a p200 pipet tip in a straight line to create a "scratch". Images were obtained by using a phase-contrast microscope (AXIO microscope with AxioCam ERc5s, Zeiss- objective 10X) in a time course of 0,6 and 24 hours, distance between edges was measured by the phase contrast microscopy and analyzed by ZEN imaging software (Zeiss). Data were represented as percentage of residual gap.

\section{Colony formation assay}

Colony formation assay was performed as described previously [38]. Briefly, about $2 \times 10^{2}$ cells were plated into a 6 -well culture. After incubation at $37^{\circ} \mathrm{C}$ for 8 days, the cells were washed twice with PBS, fixed in methanol and stained with Hematoxylin. The number of colonies were counted under microscope. Each sample was run in triplicate.

\section{Cell viability assay}

Cell Viability Assay was performed according to manufacturer's instructions of The CellTiter-Blue Cell Viability Assay (Promega). Briefly, about $2 \times 10^{3}$ cells untreated (mock) and transfected with scramble oligo or siNup153 oligos mix (60nM) in Reverse mode were added into a 96-well culture plate with three replicates for each group. The cells were incubated for 24, 48 and $72 \mathrm{~h}$. Before the test, cells were washed (with PBS, three times) 
and fresh medium (100 $\mu \mathrm{L})$ containing the CellTiterBlue $(20 \mu \mathrm{L})$ was added. The plate was incubated for $1-4 \mathrm{~h}$, protected from light at $37^{\circ} \mathrm{C}$ with $5 \% \mathrm{CO}_{2}$, before the measurement of the fluorescent signal. Background fluorescence was corrected by including control wells on each plate/time tested ( $24 \mathrm{~h}, 48 \mathrm{~h}$ and $72 \mathrm{~h})$ to measure the fluorescence from serum-supplemented culture medium in the absence of cells.

\section{HAT activity}

Measurement of the lysine acetylase (HAT) activity was analyzed as previously described [2, 39]. Briefly, Nup153-associated HAT activity was evaluated after immunoprecipitation using $400 \mu \mathrm{g}$ of protein extract. Normal IgG served as negative control. $40 \mu \mathrm{g}$ of protein extract was used to evaluate total HAT (BioVision) activity following manufacturer's instructions.

\section{Confocal microscopy}

Confocal analysis was performed as previously described [2, 12-14].

Related to Supplementary Figure 2 the cells were fixed with methanol/acetone $(1: 1)$ for $10 \mathrm{~min}$ at $20^{\circ} \mathrm{C}$ and then permeabilized for $5 \mathrm{~min}$ in $0.2 \%$ Triton-X100 in PBS. After a brief rinse non-specific sites were blocked with BSA 5\%, NGS 3\% in PBS for 1 h. The following antibodies were used for an overnight incubation: antiERß (CWK-F12, 1:250, monoclonal), anti-Nup153 ([H161], Santa Cruz \#sc-292438, 1:100, polyclonal). The following day, FITC and TRITC secondary anti-mouse and anti-rabbit antibodies (1:500, Jackson Immunological Research) were incubated for $1 \mathrm{~h}$. After washes nuclei were stained with DAPI.

Samples were analyzed with a confocal laser scanning system (TCS-SP2; Leica Microsystems and/or Nikon-Ti Eclipse equipped with a 20x-40x objective). Colocalization of the two proteins was performed analyzing z-stacked images. Confocal settings were the same for all examined samples in order to compare fluorescence intensities.

\section{Western-blot assay and co-immunoprecipitation}

Protein extracts were obtained as in [2, 12, 40]. Specifically, samples were lysed in buffer containing $50 \mathrm{mM}$ Tris- $\mathrm{HCl}$ (pH 7.4), $250 \mathrm{mM} \mathrm{NaCl}, \quad 0.1 \%$ tritonX100, 5mM EDTA, 0.3\% Empigen BB and supplemented with $1 \mathrm{mM}$ PMSF and protease inhibitor mix. Western Blot assay was performed using $40 \mu \mathrm{g}$ of total extract. Co-immunoprecipitation experiments were performed using $4 \mu \mathrm{g}$ of antibody for a range of 500$700 \mu \mathrm{g}$ of protein extract. Ademtech's Bio-Adembeads paramagnetic bead system was used to immunoprecipitate the specific proteins. A negative control was performed with the same amount of protein extract sample immunoprecipitated with the corresponding purified IgG (Santa Cruz). Total proteins were resolved by SDS-PAGE using a 3-8\% gradient and/or 10\% Invitrogen Precast gel (NuPage, TA or MES buffer). Specific protein signals were revealed with ECL Prime (Amersham, GE Healthcare) and detected by UVIDOC (Eppendorf S.r.l.). The intensity of each band was evaluated by using UVIDOC and/or the NIH Image J 1.8 software (National Institutes of Health, Bethesda, Maryland, USA). Optical density values of specific proteins were normalized to that of tubulin, H1, HSP90 or fibrillarin.

\section{RNA interference and transfection}

Small interference to Nup153 was obtained with 60nM Trilencer-27mer siRNA duplexes as oligos mix (Origene, Rockville, MD, USA) transfected by Lipofectamine RNAiMAX according to the manufacturer's instructions in hormone-deprived serum and after $48 \mathrm{~h}$ treated with $17 \beta$-estradiol $\left(E_{2}\right)$. Overexpression of ER $\beta$ was obtained with Expression vectors encoding the human ER $\beta$ full-length (530aa) or short isoform (485aa) as described [13].

\section{RNA extraction and qRT analysis}

RNA isolation, cDNA preparation and RNA quantification were performed as described [12, 13]. Briefly, real-time PCR ( $q$ RT-PCR) was repeated three times in duplicate on an ABI Prism 7500 Detection System and/or QuantStudio 5 Real-Time PCR System (Applied Biosystems). Aldolase and Gapdh served as endogenous controls.

Primers sequences, used with SYBR Green Master Mix (Applied Biosystems), were as described in [13] and as follow:

hNUP153:

5'-TGATAACATCTCAACTACCAGTGGTTT-3' and 5'-GAGAGTGAGTGAGAACGTTCAGCTT-3'.

\section{Chromatin immunoprecipitation}

Chromatin cross-linking and immunoprecipitation (ChIP) assays were performed as described [13], using antibodies specific to eNOS ( $4 \mu \mathrm{g}$; Type III, BD), ER $\beta$

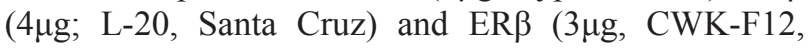
DSHB). Negative controls were generated omitting antibody (NoAb). DNA fragments were recovered and analyzed by $q$ RT-PCR as previously described [12]. Briefly, $q$ RT-PCR were performed in duplicate or triplicate and the data, normalized to the corresponding DNA input control, were represented as Fold Induction +/-E2 or as Relative enrichment A.U. (Supplementary Figure 1).

Primers sequences for promoters, designed using Primer express 3.1 (Applied Biosystems), are as follows: hNUP153 prom-eNOSpeak

5'-ACAATTTAACAACATCAACCATGTGA-3' and 5'-CAAAAGTGTAGCAAAAGGATCTGATAA-3'. 


\section{Statistical analysis}

Data are expressed as mean \pm SEM or as fold of induction as indicated in figures legend. Significance was calculated using a two-tailed $t$-test and/or one-way Analysis of Variance (ANOVA). $P$ values of $<0.05$ were considered as significant in all tests.

\section{Author contributions}

$\mathrm{AR}, \mathrm{CC}$ and $\mathrm{AF}$ conceived and designed the research; AR, CC and SN carried out experiments, analyzed and interpreted the data, performed statistical analysis and revised the manuscript; AA and LB carried out the experiments and data analysis; CG contributed reagents, materials and revised the manuscript; AP made critical revision of the manuscript text and data analysis; AF handled funding and supervision; AF, AR and $\mathrm{CC}$ wrote the manuscript. All the authors contributed critical discussion and approved the final version of the manuscript.

\section{ACKNOWLEDGMENTS}

We thank Carlo Gaetano for critical reading of our manuscript.

\section{CONFLICTS OF INTEREST}

The authors declare no competing financial interest.

\section{FUNDING}

The present study was supported by: Italian Ministry of Education, University and Research (PRIN2010TYCL9B_006) and (PRIN2015ZHKFTA) to AF and (PRIN2015HPMLFY 004) to AP; Italian Ministry of Health (RF 2010-2318330) to AF and (GR 2011-02351557) to SN; AR was recipient of a fellowship from the Italian Association for Cancer Research (AIRC).

\section{REFERENCES}

1. Vaquerizas JM, Suyama R, Kind J, Miura K, Luscombe NM, Akhtar A. Nuclear pore proteins nup153 and megator define transcriptionally active regions in the Drosophila genome. PLoS Genet. 2010; 6:e1000846. https://doi.org/10.1371/journal.pgen.1000846.

2. Nanni S, Re A, Ripoli C, Gowran A, Nigro P, D'Amario D, Amodeo A, Crea F, Grassi C, Pontecorvi A, Farsetti A, Colussi C. The nuclear pore protein Nup153 associates with chromatin and regulates cardiac gene expression in dystrophic mdx hearts. Cardiovasc Res. 2016; 112:555-67. https://doi.org/10.1093/cvr/cvw204.
3. Chow KH, Factor RE, Ullman KS. The nuclear envelope environment and its cancer connections. Nat Rev Cancer. 2012; 12:196-209. https://doi.org/10.1038/nrc3219.

4. Duheron V, Fahrenkrog B. The nuclear pore complex: structure and function. Atlas Genet Cytogenet Oncol Haematol. 2015; 19:355-75.

5. Lemaître C, Fischer B, Kalousi A, Hoffbeck AS, GuirouilhBarbat J, Shahar OD, Genet D, Goldberg M, Betrand P, Lopez B, Brino L, Soutoglou E. The nucleoporin 153, a novel factor in double-strand break repair and DNA damage response. Oncogene. 2012; 31:4803-09. https://doi.org/10.1038/onc.2011.638.

6. Orlic M, Spencer CE, Wang L, Gallie BL. Expression analysis of $6 \mathrm{p} 22$ genomic gain in retinoblastoma. Genes Chromosomes Cancer. 2006; 45:72-82. https://doi.org/10.1002/gcc.20263.

7. Heidenblad M, Lindgren $\mathrm{D}$, Jonson $\mathrm{T}$, Liedberg $\mathrm{F}$, Veerla S, Chebil G, Gudjonsson S, Borg A, Månsson W, Höglund $\mathrm{M}$. Tiling resolution array $\mathrm{CGH}$ and high density expression profiling of urothelial carcinomas delineate genomic amplicons and candidate target genes specific for advanced tumors. BMC Med Genomics. 2008; 1:3. https://doi.org/10.1186/1755-8794-1-3.

8. Shain AH, Salari K, Giacomini CP, Pollack JR. Integrative genomic and functional profiling of the pancreatic cancer genome. BMC Genomics. 2013; 14:624. https://doi.org/10.1186/1471-2164-14-624.

9. Zhou L, Panté N. The nucleoporin Nup153 maintains nuclear envelope architecture and is required for cell migration in tumor cells. FEBS Lett. 2010; 584:3013-20. https://doi.org/10.1016/j.febslet.2010.05.038.

10. Ying L, Hofseth LJ. An emerging role for endothelial nitric oxide synthase in chronic inflammation and cancer. Cancer Res. 2007; 67:1407-10. https://doi.org/10.1158/0008-5472. CAN-06-2149.

11. Lim KH, Ancrile BB, Kashatus DF, Counter CM. Tumour maintenance is mediated by eNOS. Nature. 2008; 452:64649. https://doi.org/10.1038/nature06778.

12. Nanni S, Aiello A, Re A, Guffanti A, Benvenuti V, Colussi C, Castro-Vega LJ, Felsani A, Londono-Vallejo A, Capogrossi MC, Bacchetti S, Gaetano C, Pontecorvi A, Farsetti A. Estrogen-dependent dynamic profile of eNOSDNA associations in prostate cancer. PLoS One. 2013; 8:e62522. https://doi.org/10.1371/journal.pone.0062522.

13. Nanni S, Benvenuti V, Grasselli A, Priolo C, Aiello A, Mattiussi S, Colussi C, Lirangi V, Illi B, D'Eletto M, Cianciulli AM, Gallucci M, De Carli P, et al. Endothelial NOS, estrogen receptor beta, and HIFs cooperate in the activation of a prognostic transcriptional pattern in aggressive human prostate cancer. J Clin Invest. 2009; 119:1093-108. https://doi.org/10.1172/JCI35079.

14. Re A, Aiello A, Nanni S, Grasselli A, Benvenuti V, Pantisano V, Strigari L, Colussi C, Ciccone S, Mazzetti AP, Pierconti F, Pinto F, Bassi P, et al. Silencing of 
GSTP1, a prostate cancer prognostic gene, by the estrogen receptor- $\beta$ and endothelial nitric oxide synthase complex. Mol Endocrinol. 2011; 25:2003-16. https://doi.org/10.1210/me.2011-1024.

15. Huang Z, Fu J, Zhang Y. Nitric Oxide DonorBased Cancer Therapy: advances and Prospects. J Med Chem. 2017; 60:7617-35. https://doi.org/10.1021/acs.jmedchem.6b01672.

16. Nanni S, Priolo C, Grasselli A, D'Eletto M, Merola R, Moretti F, Gallucci M, De Carli P, Sentinelli S, Cianciulli AM, Mottolese M, Carlini P, Arcelli D, et al. Epithelialrestricted gene profile of primary cultures from human prostate tumors: a molecular approach to predict clinical behavior of prostate cancer. Mol Cancer Res. 2006; 4:7992. https://doi.org/10.1158/1541-7786.MCR-05-0098.

17. Harborth J, Elbashir SM, Bechert K, Tuschl T, Weber K. Identification of essential genes in cultured mammalian cells using small interfering RNAs. J Cell Sci. 2001; 114:4557-65.

18. Galy V, Mattaj IW, Askjaer P. Caenorhabditis elegans nucleoporins Nup93 and Nup205 determine the limit of nuclear pore complex size exclusion in vivo. Mol Biol Cell. 2003; 14:5104-15. https://doi.org/10.1091/mbc.e03-04-0237.

19. Agudo D, Gómez-Esquer F, Martínez-Arribas F, NúñezVillar MJ, Pollán M, Schneider J. Nup88 mRNA overexpression is associated with high aggressiveness of breast cancer. Int J Cancer. 2004; 109:717-20. https://doi.org/10.1002/ijc.20034.

20. Aiello A, Bacci L, Re A, Ripoli C, Pierconti F, Pinto F, Masetti R, Grassi C, Gaetano C, Bassi PF, Pontecorvi A, Nanni S, Farsetti A. MALAT1 and HOTAIR Long NonCoding RNAs Play Opposite Role in Estrogen-Mediated Transcriptional Regulation in Prostate Cancer Cells. Sci Rep. 2016; 6:38414. https://doi.org/10.1038/srep38414.

21. Goetz RM, Thatte HS, Prabhakar P, Cho MR, Michel T, Golan DE. Estradiol induces the calciumdependent translocation of endothelial nitric oxide synthase. Proc Natl Acad Sci USA. 1999; 96:2788-93. https://doi.org/10.1073/pnas.96.6.2788.

22. Kim KH, Young BD, Bender JR. Endothelial estrogen receptor isoforms and cardiovascular disease. Mol Cell Endocrinol. 2014; 389:65-70. https://doi.org/10.1016/j.mce.2014.02.001.

23. Grasselli A, Nanni S, Colussi C, Aiello A, Benvenuti V, Ragone G, Moretti F, Sacchi A, Bacchetti S, Gaetano C, Capogrossi MC, Pontecorvi A, Farsetti A. Estrogen receptor-alpha and endothelial nitric oxide synthase nuclear complex regulates transcription of human telomerase. Circ Res. 2008; 103:34-42. https://doi.org/10.1161/CIRCRESAHA.107.169037.

24. Duckles SP, Miller VM. Hormonal modulation of endothelial NO production. Pflugers Arch. 2010; 459:84151. https://doi.org/10.1007/s00424-010-0797-1.
25. Nelson AW, Groen AJ, Miller JL, Warren AY, Holmes KA, Tarulli GA, Tilley WD, Katzenellenbogen BS, Hawse JR, Gnanapragasam VJ, Carroll JS. Comprehensive assessment of estrogen receptor beta antibodies in cancer cell line models and tissue reveals critical limitations in reagent specificity. Mol Cell Endocrinol. 2017; 440:138-50. https://doi.org/10.1016/j.mce.2016.11.016.

26. Andersson S, Sundberg $M$, Pristovsek N, Ibrahim A, Jonsson P, Katona B, Clausson CM, Zieba A, Ramström M, Söderberg O, Williams C, Asplund A. Insufficient antibody validation challenges oestrogen receptor beta research. Nat Commun. 2017; 8:15840. https://doi.org/10.1038/ncomms15840.

27. Kehat I, Accornero F, Aronow BJ, Molkentin JD. Modulation of chromatin position and gene expression by HDAC4 interaction with nucleoporins. J Cell Biol. 2011; 193:21-29. https://doi.org/10.1083/jcb.201101046.

28. Méjat A, Misteli T. LINC complexes in health and disease. Nucleus. 2010; 1:40-52. https://doi.org/10.4161/nucl.1.1.10530.

29. Susaki E, Nakayama KI. Multiple mechanisms for p27(Kip1) translocation and degradation. Cell Cycle. 2007; 6:3015-20. https://doi.org/10.4161/cc.6.24.5087.

30. Montanari M, Rossetti S, Cavaliere C, D'Aniello C, Malzone MG, Vanacore D, Di Franco R, La Mantia E, Iovane $\mathrm{G}$, Piscitelli R, Muscariello R, Berretta M, Perdonà $\mathrm{S}$, et al. Epithelial-mesenchymal transition in prostate cancer: an overview. Oncotarget. 2017; 8:35376-89. https://doi.org/10.18632/oncotarget.15686.

31. Mendjan S, Taipale M, Kind J, Holz H, Gebhardt P, Schelder M, Vermeulen M, Buscaino A, Duncan K, Mueller J, Wilm M, Stunnenberg HG, Saumweber H, Akhtar A. Nuclear pore components are involved in the transcriptional regulation of dosage compensation in Drosophila. Mol Cell. 2006; 21:811-23. https://doi.org/10.1016/j.molcel.2006.02.007.

32. Ando Y, Tomaru Y, Morinaga A, Burroughs AM, Kawaji H, Kubosaki A, Kimura R, Tagata M, Ino Y, Hirano H, Chiba J, Suzuki H, Carninci P, Hayashizaki Y. Nuclear pore complex protein mediated nuclear localization of dicer protein in human cells. PLoS One. 2011; 6:e23385. https://doi.org/10.1371/journal.pone.0023385.

33. Kirsh O, Seeler JS, Pichler A, Gast A, Müller S, Miska E, Mathieu M, Harel-Bellan A, Kouzarides T, Melchior F, Dejean A. The SUMO E3 ligase RanBP2 promotes modification of the HDAC4 deacetylase. EMBO J. 2002; 21:2682-91. https://doi.org/10.1093/emboj/21.11.2682.

34. Brown CR, Kennedy CJ, Delmar VA, Forbes DJ, Silver PA. Global histone acetylation induces functional genomic reorganization at mammalian nuclear pore complexes. Genes Dev. 2008; 22:627-39. https://doi.org/10.1101/gad.1632708.

35. Wang C, Tian L, Popov VM, Pestell RG. Acetylation and nuclear receptor action. J Steroid Biochem Mol Biol. 2011; 123:91-100. https://doi.org/10.1016/j.jsbmb.2010.12.003. 
36. Moehren U, Papaioannou M, Reeb CA, Grasselli A, Nanni S, Asim M, Roell D, Prade I, Farsetti A, Baniahmad A. Wild-type but not mutant androgen receptor inhibits expression of the hTERT telomerase subunit: a novel role of AR mutation for prostate cancer development. FASEB J. 2008; 22:1258-67. https://doi.org/10.1096/fj.07-9360com.

37. Barbati SA, Colussi C, Bacci L, Aiello A, Re A, Stigliano E, Isidori AM, Grassi C, Pontecorvi A, Farsetti A, Gaetano C, Nanni S. Transcription factor CREM mediates high glucose response in cardiomyocytes and in a male mouse model of prolonged hyperglycemia. Endocrinology. 2017; 158:2391405. https://doi.org/10.1210/en.2016-1960.

38. Lim SH, Jang J, Park JO, Kim KM, Kim ST, Park YS, Lee $\mathrm{J}$, Kim HC. CD133-positive tumor cell content is a predictor of early recurrence in colorectal cancer. J Gastrointest Oncol. 2014; 5:447-56.
39. Vecellio M, Spallotta F, Nanni S, Colussi C, Cencioni C, Derlet A, Bassetti B, Tilenni M, Carena MC, Farsetti A, Sbardella G, Castellano S, Mai A, et al. The histone acetylase activator pentadecylidenemalonate $1 \mathrm{~b}$ rescues proliferation and differentiation in the human cardiac mesenchymal cells of type 2 diabetic patients. Diabetes. 2014; 63:2132-47. https://doi.org/10.2337/db13-0731.

40. Re A, Nanni S, Aiello A, Granata S, Colussi C, Campostrini G, Spallotta F, Mattiussi S, Pantisano V, D'Angelo C, Biroccio A, Rossini A, Barbuti A, et al. Anacardic acid and thyroid hormone enhance cardiomyocytes production from undifferentiated mouse ES cells along functionally distinct pathways. Endocrine. 2016; 53:681-88. https://doi.org/10.1007/s12020-015-0751-2. 